\title{
Experiências e memórias na fronteira relatadas no curso de extensão Español Básico para Niños: o antes e o durante a Pandemia de COVID-19
}

\author{
Experiencias y memorias fronterizas reportadas en el curso de extensión \\ Español Básico para Niños: el antes y el durante la Pandemia de COVID- \\ 19
}

Bordering experiences and memories reported in the extension course
Basic Spanish for Children: before and after the COVID-19 Pandemic

Cristina Pureza Duarte Boéssio ${ }^{1}$

Caroline Gonçalves Feijó-Quadrado²

\begin{abstract}
Resumo
O objetivo deste texto é apresentar e discutir o desafio das memórias, proposto às crianças participantes do Curso de Extensão Español Básico para Niños, ofertado pela Universidade Federal do Pampa - campus Jaguarão. A intenção do desafio foi resgatar e valorizar experiências e memórias interculturais, da fronteira entre Jaguarão Brasil e Rio Branco - Uruguay, que fazem parte da vida dos sujeitos envolvidos: as crianças, as alunas do curso, seus familiares e os proponentes do curso. Metodologicamente, os dados foram obtidos através de reunião síncrona, realizada através do Google Meet, e registros efetuados no Grupo de WhatsApp do Curso. A partir da análise realizada, os resultados indicam que, de modo geral, as experiências e memórias que mais emergiram dos participantes estão relacionadas à: a) relação entre os povos em uma zona de fronteira (fronteiriços? Ou brasileiros e uruguaios?); b) curiosidades sobre questões relativas à língua; e c) naturalidade de atravessar a ponte e estar em outro país, em contraste com a burocracia vista no tempo de pandemia.
\end{abstract}

Palavras-Chave: Espanhol para crianças; Experiências do vivido; Memórias; Fronteira.

\section{Resumen}

El propósito de este texto es presentar y discutir el desafío de las memorias, propuesto a los niños que participan del Curso de Extensión Español Básico para Niños, impartido en la Universidade Federal de Pampa - campus Jaguarão. La intención del desafío fue rescatar y valorar experiencias y recuerdos interculturales, de la frontera entre Jaguarão - Brasil y Rio Branco - Uruguay, que son parte de la vida de los sujetos involucrados, ellos son: los niños, estudiantes del curso, sus familias y los proponentes del programa. Metodológicamente, los datos se obtuvieron a través de una reunión sincrónica, realizada a través de Google Meet, y de registros en el Grupo WhatsApp del Curso. A partir del análisis realizado, los resultados indican que, en general, las vivencias y recuerdos que más surgieron de los participantes se relacionan con: a) la relación entre los pueblos de una zona fronteriza (¿fronterizos? O ¿brasileños y uruguayos?); b) curiosidades sobre cuestiones lingüísticas; y c) la naturalidad de cruzar el puente y estar en otro país, en contraste con la burocracia de la época de la pandemia.

Palabras claves: Español para Niños; Experiencias de lo vivido; Memorias; Frontera.

\footnotetext{
${ }^{1}$ Doutora em Educação; Docente na Universidade Federal do Pampa - Unipampa/Jaguarão; Jaguarão, Rio Grande do Sul; Brasil; cristinacpd@ hotmail.com.

${ }^{2}$ Mestra em Educação; Assistente em Administração na Universidade Federal do Pampa - Unipampa/Jaguarão; Jaguarão, Rio Grande do Sul; Brasil; carolinefeiijo@gmail.com.
} 


\begin{abstract}
The purpose of this text is to present and discuss the challenge of the memories, proposed to children participating in the Extension Course Basic Spanish for Children, offered by the Federal University of the Pampa -Jaguarão campus. The intention of the challenge was to retrieve and value intercultural experiences and memories from the border between Jaguarão - Brazil and Rio Branco - Uruguay, which is part of the life of the subjects involved: the children, the course students, their families and the course proponents. Methodologically speaking, the data was obtained through a synchronous meeting, held through Google Meet, and records from the Course WhatsApp Group. Based on the analysis carried out, the results show that, in a general way, the experiences and memories that arose the most from the participants were related to: a) the relationship between the people in a bordering zone (Brazilians and Uruguayans); b) curiosities concerning the language; and c) the ease of crossing the bridge and being in another country, in contrast with the bureaucracy seen during the pandemic.
\end{abstract}

Keywords: Spanish for children; Daily life experiences; Memories; Border.

\title{
1. Introdução
}

Desde o ano de 2007, trabalhamos em um projeto de Extensão denominado Español Básico para Niños em uma Universidade pública na fronteira Brasil/Uruguay. Desde lá, muitas foram as propostas realizadas e muitos artigos sobre o tema foram publicados. Nosso trabalho com as crianças era realizado aos sábados, pela tarde, na Universidade.

Quando estávamos prontos para começar o Módulo III, no primeiro semestre de 2020, (são 3 módulos de 40h semestrais), instaura-se a Pandemia de COVID-19, trazendo dores, mortes, tristezas, medos, enfim, tudo aquilo que nunca se havia imaginado. Mas, além de todo o mal que este vírus vem provocando, trouxe-nos, também, uma oportunidade de reflexão.

Nunca havíamos imaginado realizar um trabalho remoto com essas crianças, pois atuávamos em uma perspectiva de Turismo Pedagógico, na qual realizávamos idas ao país vizinho para uma imersão e aprendizado/aquisição ${ }^{3}$ em contexto real, além das atividades práticas no seio da Universidade. Eis que, de repente, tudo muda, e nos vemos impelidos a seguir nosso trabalho, inclusive por solicitação dos pais ou responsáveis, e mesmo das crianças, agora então, à distância.

Decidimos, enquanto grupo executor do curso de extensão, e por sugestão dos responsáveis de que seguíssemos trabalhando, enviar, semanalmente, desafios aos pequenos,

\footnotetext{
3 Cabe destacar que, apesar de Krashen (1982, 1985) fazer a distinção entre aprendizagem e aquisição, explicando cada uma delas, optamos em nossos trabalhos, tratá-las como sinônimos, pela maneira que propomos este ensino, e, portando apresentação do mundo real, para estas crianças. Buscamos sempre um contexto real, ou o mais próximo do real possível. Na mesma perspectiva de Jonhson que acredita que tanto a aprendizagem pode se tornar em aquisição, como a aquisição pode se tornar aprendizagem. Podemos citar trabalhos em que já se discutiu isso (AUTOR, 2010).
} 
considerando esse novo momento em que estamos vivendo. A ideia foi dar atenção a temas direcionados, principalmente, à saúde, meio ambiente, reciclagem, alimentação saudável, cultivo de alimentos orgânicos, entre outros. Dentre os desafios propostos, vamos apresentar, aqui, o que buscou resgatar e valorizar experiências e memórias interculturais, desta região de fronteira, que fazem parte da vida dos sujeitos envolvidos: as crianças, alunas do curso, seus familiares e os proponentes do curso. De acordo com Larrosa (2002, p. 19), devemos "pensar a educação a partir do par experiência/sentido”. Nessa perspectiva é que trabalhamos.

Este texto está organizado nesta introdução, no marco teórico que sustenta nossa proposta, no contexto, no desafio e nas memórias, juntamente com suas análises e, por último, em algumas considerações finais.

\section{Marco teórico}

Nossos estudos para o ensino de espanhol para crianças vêm, ao longo do tempo, quase 14 anos, ancorando-se, basicamente, em Krashen (1982, 1985) e em suas cinco hipóteses. Mas, prioritariamente, na distinção que faz entre aquisição e aprendizagem, na hipótese do filtro afetivo e na do input (AUTOR, 2010). Já discutimos bastante sobre essas questões e também quanto ao Turismo Pedagógico, já que estamos localizados em uma região de fronteira Brasil/Uruguay, e a imersão na língua e na cultura do país vizinho sempre fez parte do nosso trabalho. Seguindo a concepção de Larrosa (2002, p. 24-26), acreditamos que

[...] é experiência aquilo que "nos passa", ou que nos toca, ou que nos acontece, e ao nos passar nos forma e nos transforma. Somente o sujeito da experiência está, portanto, aberto à sua própria transformação.

Nessa mesma perspectiva, Aquilino Sánchez (2000, p. 69) apresenta o pensamento de Comenio, do prólogo de seu livro Orbis Sensualium (1659) que é: "Pues no hay nada en la mente que previamente no haya entrado por los sentidos... porque los sentidos buscan sus propios objetos... y si éstos no están presentes se tornan vagos y desvarían” (AUTOR, 2010, p. 03).

Desde 1659, portanto, século XVI, os pensadores já apontavam a importância da experiência, dos sentidos; o que fica na memória é o que entra pelos sentidos e assim deve ser a Educação, caso contrário, está fadada a pouca ou nenhuma produtividade.

Por isso, destacamos a importância da aprendizagem/aquisição em contexto real, em interação com os falantes da língua alvo, em imersão no cotidiano, na cultura, no idioma que 
está sendo ensinado/apresentado, possibilitando, assim, que essas crianças tenham experiências reais com o uso da língua.

Sobre isso, nos ancoramos em Larrosa (2002, p. 26-27), para quem,

[...] o saber de experiência se dá na relação entre o conhecimento e a vida humana. De fato, a experiência é uma espécie de mediação entre ambos. É importante, porém, ter presente que, do ponto de vista da experiência, nem "conhecimento" nem "vida" significam o que significam habitualmente.

Percebemos que sempre que oportunizamos às crianças o contato direto com a cultura do país vizinho e seu idioma, surpreendemo-nos positivamente com as reflexões feitas por elas. Nesse sentido, quem acaba aprendendo e tendo experiências que realmente contribuem em nossa formação/transformação, somos nós.

Agora, neste momento em que nos está imposto um isolamento social para a preservação de nossas vidas e a de todos, e que estamos buscando nos adaptar a um novo normal, a uma nova lógica (que não sabemos bem, qual é...) através do trabalho remoto, pensamos em valorizar as experiências dos sujeitos, já que, de acordo com Larrosa (2002, p. 21)

[...] a experiência é o que nos passa, o que nos acontece, o que nos toca. Não o que se passa, não o que acontece, ou o que toca.-A cada dia se passam muitas coisas, porém, ao mesmo tempo, quase nada nos acontece. Dir-se-ia que tudo o que se passa está organizado para que nada nos aconteça.1 Walter Benjamin, em um texto célebre, já observava a pobreza de experiências que caracteriza o nosso mundo. Nunca se passaram tantas coisas, mas a experiência é cada vez mais rara.

Nesse sentido, buscamos provocar os responsáveis, as crianças e os próprios proponentes do curso de Español Básico para Niños sobre suas experiências em relação à fronteira Jaguarão - Brasil, Rio Branco - Uruguay, a trazerem à memória e a compartilhar suas vivências na fronteira, com questões culturais e linguísticas que possam (re)significar, quem sabe, o ensino/apresentação e o aprendizado/aquisição da língua espanhola.

Nossa vida passa muito rápido. Nunca achamos tempo para alguns aspectos essenciais, porque estamos sempre correndo. Nesse sentido, Larrosa (2002, p. 23) alerta que "a experiência é cada vez mais rara, por falta de tempo. Tudo o que se passa, passa demasiadamente depressa, cada vez mais depressa". Alega também que "por isso, a velocidade e o que ela provoca, a falta de silêncio e de memória, são também inimigas mortais da experiência" (LARROSA, 2002, p. 23). 
Com foco nessas ideias e com essa oportunidade que a pandemia de COVID-19 nos traz, de diminuirmos a velocidade, de estarmos mais tempo em casa e em família, de poder conversar sobre as memórias, é que pensamos em valorizar as experiências vividas, contrastando o período em que cruzávamos livremente a fronteira, com a realidade de hoje. Pois, ainda fazendo eco às palavras de Larossa (2002, p. 24), acreditamos que

[...] a experiência, a possibilidade de que algo nos aconteça ou nos toque, requer um gesto de interrupção, um gesto que é quase impossível nos tempos que correm: requer parar para pensar, parar para olhar, parar para escutar, pensar mais devagar, olhar mais devagar, e escutar mais devagar; parar para sentir, sentir mais devagar, demorar-se nos detalhes, suspender a opinião, suspender o juízo, suspender a vontade, suspender o automatismo da ação, cultivar a atenção e a delicadeza, abrir os olhos e os ouvidos, falar sobre o que nos acontece, aprender a lentidão, escutar aos outros, cultivar a arte do encontro, calar muito, ter paciência e dar-se tempo e espaço.

Percebemos, então, que este é o momento de olhar mais devagar, escutar mais devagar; apesar de que a "arte do encontro", neste momento de pandemia, tenha que ser reinventada, tentar conduzir nossas ações na perspectiva de Larrosa (2002). Buscando valorizar as experiências e suas memórias é que propusemos o novo desafio.

Para Larrosa (2002, p. 27),

\begin{abstract}
O saber da experiência é um saber que não pode separar-se do indivíduo concreto em quem encarna. Não está, como o conhecimento científico, fora de nós, mas somente tem sentido no modo como configura uma personalidade, um caráter, uma sensibilidade ou, em definitivo, uma forma humana singular de estar no mundo, que é por sua vez uma ética (um modo de conduzir-se) e uma estética (um estilo).
\end{abstract}

Propondo este desafio, temos como objetivos: valorizar as experiências e memórias dos sujeitos; registrar memórias de acontecimentos interessantes em uma região de fronteira, que contenham situações curiosas culturais, linguísticas ou outras, (re)significar o tempo e as relações humanas durante a Pandemia e, por fim, dar vez e voz aos sujeitos envolvidos, conhecendo suas memórias.

Não sabemos, realmente, se estamos ensinando ou oferecendo oportunidades para que essas crianças descubram, por si só, tornando-se, assim, os sujeitos da experiência e despertando o saber da experiência, que, segundo Larrosa (2002, p. 27)

[...] é um saber particular, subjetivo, relativo, contingente, pessoal. Se a experiência não é o que acontece, mas o que nos acontece, duas pessoas, ainda que enfrentem o mesmo acontecimento, não fazem a mesma experiência. 
A partir das concepções teóricas apresentadas, a próxima sessão trará, com mais detalhes, o contexto da pesquisa e os resultados obtidos através do desafio das memórias.

\section{O CONTEXTO, O DESAFIO E AS MEMÓRIAS}

\subsection{0 contexto e o desafio}

Primeiramente, cabe localizar o leitor, apresentando o contexto em que vivemos. É uma região de fronteira: a cidade brasileira Jaguarão, no Rio Grande do Sul, e a cidade uruguaia Rio Branco em Cerro Largo. São separadas pelo Rio Jaguarão e unidas pela ponte internacional Mauá. Cruzar a ponte era uma situação cotidiana para os moradores de ambas as cidades, que, inclusive, faziam caminhadas, saídas de bicicleta, compras nos free shoppings, entre outras atividades. Atualmente, devido à pandemia de COVID-10, a situação não é a mesma. O exército, a polícia e a vigilância sanitária estão na ponte, dos dois lados, medindo a febre, pedindo documentos e causando certo desconforto e uma situação constrangedora, algumas vezes.

A partir daí, resolvemos questionar que memórias de fronteira os envolvidos no Curso de Extensão Español Básico para Niños têm, e que impacto essa pandemia causou em nossas vidas. Para isso, propusemos um desafio, no qual cada um dos participantes deveria contar alguma memória relacionada à fronteira e, se possível, que as crianças entrevistassem outros familiares para saber que memórias possuem.

Metodologicamente, para obtenção dos dados, realizamos uma reunião online através da plataforma Google Meet e, também, lançamos o desafio através do Grupo de WhatsApp Español para Niños, que conta com a participação de pais e alunos do Projeto de Extensão, além dos membros da equipe executora. Os dados obtidos na reunião foram transcritos e, juntamente com as informações recebidas via grupo de WhatsApp, foram analisados.

\subsection{As memórias}

Caroline (Reunião Meet, 22/08/2020), uma das proponentes do Curso, relatou que, antes da pandemia, ia com frequência à cidade uruguaia, vizinha, Rio Branco, comprar incensos. Contou que entrava na lojinha, escolhia, sentia os cheiros de cada um e era muito bem atendida. Por outro lado, no momento em que estamos vivendo, essa situação mudou um pouco. Em sua última ida, em junho de 2020, a vendedora pediu que ela ficasse na porta. 
Também comentou que no Brasil havia muitos casos de COVID-19, e que as políticas brasileiras não estavam contribuindo para o enfrentamento da pandemia, coisa que difere do Uruguay. Caroline relata que, naquele momento, sentiu que o fato de ela ser brasileira gerou certa preocupação por parte da vendedora.

Esta situação nos faz refletir a respeito de nossas próprias crenças e meios de agir em sociedade. Também nos faz questionar a própria relação existente entre dois povos em uma região de fronteira, principalmente considerando uma situação de adversidade, como é o caso de uma pandemia. Antes, quando não havia nenhum tipo de risco, nem a necessidade desse tipo de "cuidados", éramos tratados como irmãos, na maioria das vezes, o que agora parece que não está mais acontecendo. A distinção de que pertencemos a nações diferentes, com políticas públicas e cuidados diferenciados, parece estar mais acentuada.

Cristina (Reunião Meet, 22/08/2020) também relata que, antes da pandemia, participava de corridas de bicicletas no Uruguay com frequência, pois geralmente há uma ou duas no meio do ano e uma no verão, no Lago Merin e que, sempre, brasileiros e uruguaios fazem parte desses eventos como "irmãos", que há ampla divulgação de "las carreras" e que o que mais importa é o grande número de participantes. Relata que ficou surpresa num domingo de setembro de 2020, indo de carro para o Lago Merin, observava várias bicicletas vindo em sentido contrário com números de competidores pendurados. No final do dia, vê nas redes sociais as premiações de "las compañeras uruguayas" por conta da corrida. Surpresa, felicita e questiona uma amiga que participou. Perguntou quando foi, que não havia visto nada e por que não tinha sido avisada... Como resposta, obteve que não pode ser divulgada a corrida porque não seria permitida a participação de brasileiros devido à Pandemia de Covid-19. Cristina relata que ficou perplexa, com um misto de tristeza e a percepção do preconceito.

Essas memórias e reflexões emergentes do contexto de pandemia, que nos fazem refletir acerca da relação entre os povos em uma zona fronteiriça, são contrastadas por relatos que demonstram curiosidades a respeito de questões relativas à língua. Isso ficou evidente em outro depoimento de Cristina e, também, em uma manifestação de Tiago, membro da equipe executora.

Cristina (Reunião Meet, 22/08/2020) observou que as expressões "ala maula" e "a las pucha" (que demonstram surpresa), muito utilizadas por seu avô quando ela era criança, ainda que ele não residisse em Jaguarão, e sim um pouco mais distante da fronteira, são utilizadas pelos uruguaios residentes nesta região. Também a expressão "tá pelada a coruja" ou "tá pelado" do português (que significa estar pronto, estar terminado, estar resolvido), também se encontra neste contexto fronteiriço, como: "ta pelao" sic [pelado], com o mesmo significado. 
Já Tiago (Reunião Meet, 22/08/2020) conta que seu pai era uruguaio e que, em certa ocasião, teria dito que levaria os filhos ao Uruguay para comprar caramelos. As crianças ficaram curiosas para conhecer os tais "caramelos" (famosos no Uy), e, quando lá chegaram, sentiram-se um pouco desapontadas, pois os caramelos não passavam de balas.

Outro relato interessante foi de Larissa (Reunião Meet, 22/08/2020), integrante da equipe executora que trabalha na única escola particular da cidade de Jaguarão. Para os moradores de Jaguarão, cruzar a ponte e estar no Uruguay, antes da pandemia, era a atitude mais natural do mundo, mas percebemos que, para quem vem de fora, essa naturalidade não se aplica. Larissa conta que, na escola onde trabalha, é muito comum esse estranhamento por alunos que vêm de fora da cidade, às vezes até de bem longe, por motivo do quartel, já que há muito trânsito de militares. Como exemplo, relata que um aluno novo, vindo do norte do Brasil, dizia estar muito ansioso, pois, no dia seguinte, iria conhecer outro país. A criança contava, com entusiasmo, a todos os colegas, a aventura que iria realizar. Quando relatou que era o Uruguay, os colegas se divertiram, ou nem se espantaram, devido ao fato de não perceberem a cidade vizinha como outro país.

Nessa mesma perspectiva, Cristina (Reunião Meet, 22/08/2020), a coordenadora do projeto, relata que um colega seu, da universidade, vindo de longe para residir em Jaguarão, lhe havia pedido que o levasse para comprar uma bicicleta. Ela se dispôs e foram de carro. $\mathrm{O}$ colega nervoso, perguntou: "Mas, como vamos entrar assim? Não precisamos de visto? Não vão nos parar?" Cristina se surpreendeu com as perguntas, já que, para os residentes desta fronteira, esse trânsito era um rito cotidiano, antes da pandemia.

A naturalidade de atravessar a fronteira mencionada tanto por Cristina quanto por Larissa é vista de outra forma no atual contexto de pandemia. Caroline e Paulo, pai de João Inácio, um dos alunos do Curso, mencionam que, durante a pandemia, ir para o Uruguai passou a ser mais difícil.

Caroline (WhatsApp, sexta-feira 28/08/2020, às 19:53) menciona a burocracia exigida para atravessar a ponte devido à necessidade de identificação e ao movimento acentuado de carros, e demonstra, por sua fala, como esse fato tem afetado sua rotina e de seus familiares.

[...] Estava conversando com meu cunhado por whats sobre exercício físico e ele me disse que antes da pandemia estava caminhando na ponte, que já tinha emagrecido quase 20 quilos com as caminhadas e alimentação. Depois da pandemia, ele parou de caminhar e um dos motivos foi a burocracia para passar para o Uy, de apresentar identidade e comprovante de residência. 
O Gil e eu também íamos pedalar no Uy direto antes da pandemia, mas depois da pandemia, também pela burocracia e pela função de sempre ter muito movimento na ponte, acabamos optando por parar de ir para o lado de lá

Fiquei pensando sobre como esse período limitou muito nossas idas e vindas, algo que era tão natural para nós, né? Vocês também sentiram algo parecido?...

(Caroline, via WhatsApp, sexta-feira 28/08/2020, às 19:53).

Já Paulo (WhatsApp, sexta-feira 28/08/2020, às 20:33) complementou contando que, antes da pandemia,

Todo fim de semana nós atravessávamos a ponte para ir na Lagoa Mirim, recorria os bairros, pois tem uma praça linda na Tablada, na volta nossa paradinha obrigatória na praça da Coxilha para comer torta frita e olhar os artesanatos. O João Inácio adorava brincar de patins ou patinete, sempre levávamos a avó que gostava de fazer exercícios nos aparelhos de ginástica. E para finalizar a tarde, o pôr do sol no cais de Jaguarão.

Mas com a Pandemia ficamos limitados; do serviço para casa, sem poder sair e sem contato físico com a avó.

Até minhas pedaladas que fazia antes até a Lagoa, deixei de fazer pelo transtorno na ponte. Mudou totalmente nossa rotina (Paulo, WhatsApp, sexta-feira 28/08/2020, às 20:33).

Todas as memórias apresentadas até aqui demonstram as experiências que mais tocaram (LARROSA, 2002) os integrantes do Curso de Español Básico para Niños com relação à fronteira, tanto antes quanto durante a pandemia de COVID-19. A partir da recorrência do que foi apresentado, identificamos que os dados podem ser organizados em três temas principais: a) A relação entre os povos em uma zona de fronteira (fronteiriços? Ou brasileiros e uruguaios?); b) Curiosidades sobre questões relativas à língua; e c) a naturalidade de atravessar a ponte e estar em outro país, em contraste com a burocracia vista no tempo de pandemia.

Sobre o item A relação entre os povos em uma zona de fronteira, a reflexão que emergiu esteve relaciona à maneira como os moradores da região costumavam se relacionar antes da pandemia e aos desafios observados no contato durante o período de cuidados devido ao COVID-19. A proximidade e a visão de que eram todos "hermanos" ou "fronteiriços", nem brasileiros, nem uruguaios, foi substituída por uma possível impressão que, de fato, em momentos de adversidade, principalmente quando esta está relacionada a questões de saúde, as nacionalidades distintas são pontos bastantes destacados e reconhecidos no contexto. Isso porque, mesmo havendo muitas proximidades linguísticas, culturais e de influências na formação de identidade dos sujeitos, o fato de que eles pertencem a países diferentes é afirmado pelo contraste das políticas adotadas por cada um. 
Já as Curiosidades sobre questões relativas à língua emergiram a partir de relatos que destacavam palavras e expressões como "caramelo"; "ala maula" e "a las pucha"; "tá pelada a coruja" ou "tá pelado" e "ta pelao". Este tópico evidencia as aproximações e as influências linguísticas que ocorrem na fronteira.

Por último, A naturalidade de atravessar a ponte e estar em outro país, em contraste com a burocracia vista no tempo de pandemia foi outro ponto que apareceu com recorrência. Inicialmente, o relato de Larissa e o fato de seus alunos nem perceberem que a cidade vizinha pertence a outro país pode ser resultado da facilidade e da liberdade de ir e vir e, também, das mesclas linguísticas e culturais. Esse ir e vir, que para nós é natural, causa estranhamento para quem não é da região que, diferente dos moradores daqui, enxergam o Uruguai como outro país e, por isso, perguntam se "Não precisamos de visto".

Partindo das análises realizadas, o próximo tópico abordará as considerações finais, apontando os resultados obtidos e os novos desafios do grupo a partir do que foi realizado até aqui.

\section{Considerações finais}

Este texto teve o objetivo de apresentar o desafio que buscou resgatar e valorizar experiências e memórias interculturais desta região de fronteira, que fazem parte da vida dos sujeitos envolvidos no Curso de Extensão Español Básico para Niños, para conhecermos e refletirmos sobre elas, num período de Pandemia de COVID-19, em que os tempos e as interações são outros.

Percebemos que nem todos os integrantes do Projeto fizeram relatos sobre as memórias, muitas das crianças alegaram estar envolvidas com as atividades escolares, não tendo tempo para completar este desafio. Por isso, a intenção que tínhamos no início de que os alunos entrevistassem seus familiares não se efetivou. Os responsáveis alegam que querem que sigamos com as propostas, mas que as questões escolares e o trabalho remoto de alguns dificultam o cumprimento das tarefas.

A partir dessa atividade também ficou evidente um novo desafio para o grupo proponente do projeto - pensar novas formas para buscar maior envolvimento das crianças e de seus responsáveis, visando a uma maior interação. Ainda estamos em processo de descobrir a melhor alternativa para comunicação. Iniciamos com desafios semanais pelo Grupo do WhatsApp e, depois, fizemos três encontros síncronos semanais com as crianças através do Google Meet, aos sábados, no horário em que seriam as aulas presenciais. Porém, 
nos encontros através do Meet, contamos com a participação efetiva de apenas 2 alunos, por isso, optamos por voltar aos desafios por WhatsApp, incluindo um encontro síncrono para conversação apenas no final de cada mês, e não mais semanal.

Sobre a análise dos dados obtidos especificamente através do desafio das memórias, como já mencionado, com base na recorrência do que foi apresentado, os temas principais presentes nos depoimentos foram organizados nos seguintes tópicos: a) A relação entre os povos em uma zona de fronteira (fronteiriços? Ou brasileiros e uruguaios?); b) Curiosidades sobre questões relativas à língua; e c) A naturalidade de atravessar a ponte e estar em outro país, em contraste com a burocracia vista no tempo de pandemia.

A partir dos dados analisados, a pandemia, de certo modo, tem trazido experiências aos moradores que revelam a noção de que, na realidade, embora tenhamos muitas proximidades, somos cidadãos de duas nações diferentes. A burocracia, o movimento acentuado e a dificuldade em atravessar a ponte foram aspectos elencados que podem ter contribuído com essa experiência e que demonstraram, também, certa limitação para o ir e vir que, até então, era natural.

Diante de todas essas reflexões, optamos por terminar nosso texto na esteira das reflexões de Morin (2002, p. 25-26), para quem

\begin{abstract}
viver é uma aventura que implica incertezas sempre renovadas, eventualmente com crises ou catástrofes pessoais e/ou coletivas. Viver é enfrentar incessantemente incerteza, inclusive diante da única certeza, que é nossa morte, da qual não conhecemos a data. Não sabemos onde e quando seremos felizes ou infelizes, não sabemos de que enfermidades sofreremos, não conhecemos com antecedência nossas fortunas e infortunas. Entramos em uma grande época de incertezas sobre nossos futuros, o de nossa sociedade, o de nossa humanidade mundializada.
\end{abstract}

Por essas razões, pensamos que o refletir sobre memórias do vivido e da situação atual de incertezas e medo seria provocador no sentido de perceber as mudanças e o compromisso que temos com o resgate das vivências e com o cuidado com o meio ambiente, com a saúde e com o próximo.

"A nova sabedoria implica a compreensão de que toda vida pessoal é uma aventura inserida em uma aventura social, ela mesma inserida na aventura da humanidade" (MORIN, 2015, p.37). E, para isso, acreditamos que observar memórias do vivido pode, de certa forma, nos fazer pensar em como tornar este presente e futuro, incertos, mais interessantes, mais humanos, e mais comprometidos com a vida da Mãe Terra. 


\section{Referências}

AUTOR. 2010.

LARROSA, Jorge Bondía. Notas sobre a experiência e o saber da experiência. Rev. Bras. Educ. [online]. 2002, n. 19, p. 20-28. ISSN 1413-2478. Disponível em: http://www.scielo.br/pdf/rbedu/n19/n19a02.pdf. Acesso em: agosto. 2020.

MORIN, Edgar. Ensinar a viver: Manifesto para mudar a educação. Porto Alegre, Ed. Sulina, 2015.

SANTOS, Boaventura de Sousa. A cruel pedagogia do vírus. Portugal: Edições Almedina, 2020. 